\title{
EL PODER BLANDO DE LA MARCA-PAÍS: DEL MARKETING A
}

\section{LA DIPLOMACIA PÚBLICA}

José Luis Saavedra Torres1

Universidad del Zulia

saavedra.mktg@gmail.com

Material original autorizado para su primera publicación en la revista académica REDMARKA. Revista Digital de Marketing Aplicado.

https://doi.org/10.17979/redma.2012.01.08.4738

Recibido: 19 Febrero 2012

Aceptado: 5 Junio 2012

\section{RESUMEN}

El artículo tiene como propósito analizar la aplicación de la Marca-País como herramienta de diplomacia pública en la estrategia de política internacional de los Estados. En este sentido se hace una revisión bibliográfica sobre tres cuerpos teóricos a vincular: el concepto de Marca-País, la teoría dualista de Kagan (2003) y de Nye (2004), y las concepciones de Estado posmoderno de Noya (2005) y Van Ham (2008). Se concluye la Marca-País tiene el poder de transmitir valores que legitimados en un contexto internacional pueden influir en las decisiones de Estados nacionales. Esta regulación de conductas es un proceso explicable a través de los postulados constructivistas, evidenciándose un vacío teórico para explicar estos mecanismos en contextos de índole regional, continental y/o mundial.

Palabras Clave: Marca-País, Poder Blando, Diplomacia Pública.

1 Universidad del Zulia. Facultad de Ciencias Económicas y Sociales. División de Estudios para Graduados. Av. 16 (Guajira), Ciudad Universitaria "Dr. Antonio Borjas Romero". Núcleo Humanístico. Maracaibo, Venezuela. Telf: (58) 2614126546 


\section{ABSTRACT}

SOFT POWER AND PLACE BRANDING: FROM MARKETING TO PUBLIC POLICIY

The purpose of the article is to analyze the application of the Place Branding as tool of Public Diplomacy in the international strategy of States. A bibliographical review is done to linking three theoretical bodies: Place Branding concept, the dualistic theory of Kagan (2003) hard power and Nye (2004) soft power, and the conceptions of Postmodern State (Noya, 2005) and Van Ham (2008). Concluding that Place Branding has the power to transmit values that legitimized in an international context could influence national decisions. This process is an explicable across the constructivism concept, where a theoretical void is showed to explain these mechanisms in contexts of regional, continental and / or world spectrum

Key Words: Place Branding, Soft Power, Public Diplomacy. 


\section{INTRODUCCIÓN}

Inmediatamente después de los hechos del 11 de septiembre, el Secretario de Estado de EEUU, Colin Powell, definió la diplomacia estadounidense de este modo: "Estamos vendiendo un producto. El producto que vendemos es la democracia".

Y como todo buen producto se desarrolló una estrategia de comercialización donde la democracia tuvo un desarrollo de valores de marca (libertad, igualdad, comunicación), un desarrollo comunicacional (campaña mediática en medios masivos del oriente medio) y hasta un soporte de marca-fabricante: El uso del nombre, símbolos y valores de EEUU como marca-país.

Sin embargo esta propuesta de utilizar el país, y todo lo que en sí mismo representa como referencia, soporte o sustento para impulsar aspectos de interés económico, político y/o social para una nación, no es algo nuevo. La primera referencia de esfuerzos promocionales de países, estados y regiones es el plan realizado por Inglaterra e Irlanda a fines del siglo XVII para impulsar la economía de sus ciudades (Borsay y Proudfoot, 2002). Ward (1998) recopiló experiencias en Europa y USA desde 1850 al 1998; entre otros.

Lo novedoso de la afirmación de Colin Powell es que por primera vez, un Estado hace ex profeso su intención de utilizar la Marca-País como una herramienta del ámbito político y de su política exterior, y no como una herramienta de mercadeo para atraer la atención y el interés de turistas, inversionistas e inmigrantes (Anholt y Hildreth, 2004).

En este contexto nace el objetivo del presente ensayo documental, que se plantea analizar la aplicación de la Marca-País como herramienta de diplomacia pública en la estrategia de política internacional de los Estados. Para lograr este objetivo, se desarrolló una metodología que estuvo enfocada en la revisión bibliográfica- documental a través de análisis de contenidos de textos de diferentes autores y artículos científicos publicados en revistas arbitradas. 


\section{UN PAÍS COMO MARCA}

En un mundo globalizado e interconectado, las ciudades, regiones y países compiten entre sí para obtener recursos financieros internos, inversión foránea, capital humano, flujo turístico, entre otros (Homs, 2004). Solamente en Europa existen 500 regiones y más de 100 mil comunidades individuales compitiendo por los mismos escasos recursos (Kotler y col. 1999).

La existencia de experiencias tan variadas y diversas de aplicación de conceptos de Marca-País y Marca-Ciudad han creado un extenso debate interdisciplinario en el que profesionales de las ciencias sociales y el sector público; han convertido al Mercadeo de Lugar en una característica prominente de la estrategia del desarrollo económico (Seisdedos, 2006).

La Marca-País es un concepto de estructura cognitiva que se vincula a cómo codifican información los consumidores sobre marcas producidas en diferentes países, y sobre lo que significan cada uno de los países en sí mismos (Fan, 2006). En este sentido, los consumidores mantendrán categorías cognitivas distintas según los países y marcas de que se trate (Lucarelli y Berg, 2011).

La Imagen de un País es la base para la construcción de una Marca-País estable. El conjunto de activos y pasivos vinculados al nombre y símbolo del país incorporan o sustraen el valor suministrado por un producto oriundo de esa nación o servicios turísticos allí ofrecidos (Sánchez, Cubillo y Cerviño, 2005). Una Imagen País con una base rica cognitiva, se asociará a un mayor nivel de confianza y disfrutará de mayor disponibilidad, impulsando actitudes y comportamientos más coherentes (Anholt, 2008).

Según Casilda (2001:3): "está demostrado que los estereotipos nacionales y culturales influyen en las percepciones y evaluaciones. Los consumidores han desarrollado una serie de creencias sobre las marcas provenientes de otros países. Aunque estos estereotipos pudieran resultar sesgados, suelen desempeñar un papel constructivo y aportar coherencia a los procesos de decisión. Si la información sobre los atributos de la marca es confusa, el país de origen pasará a ser la variable de evaluación". 
Galiano (2002) remarca la importancia de diferenciar entre la marca y la imagen de país. La imagen de un país siempre existe, siempre que se conozca acerca de la existencia de tal país, mientras que no ocurre lo mismo con las marcas; por este motivo la imagen de un país influye sobre la imagen de las marcas de este país. Junto con la imagen país previamente formada, las experiencias personales, información adquirida y las creencias estereotipadas sobre países, los consumidores generan imágenes de marca país. (González y Casilda, 2002).

Por todo lo anterior, se ha hecho cada vez más indispensable el desarrollo de Estrategias de Marca-País (EMP) para mitigar este efecto. A tal respecto, Iglesias y Molina (2008:111) definen la EMP "como el uso de características típicas de la vida nacional como medio de influir en la imagen y percepción del país en la sociedad civil, la opinión pública y los medios de comunicación extranjeros, incrementando el prestigio internacional del Estado y mejorando su posición política y su competitividad económica en el sistema mundial".

Al respecto, el desarrollo de una EMP tiene como objetivo final crear y transmitir una Imagen País (activo intangible) que se acompaña con una Marca País (logotipo, slogan y lema) que engloba a las sub-marcas bienes, productos y servicios nacionales (Iglesias y Molina; 2008). Como estrategia, la EMP es emprendida y asumida directamente por el gobierno de un país junto con actores de la sociedad civil, implicándose el sector público y el privado tanto en la etapa del diseño como en la implementación ya que ambos sectores obtendrán a la larga beneficios por igual de esta decisión (Anholt, 2008).

\section{FORMACIÓN DE LA IMAGEN-PAÍS}

Basado en el concepto que la Imagen del País pre-configura las percepciones y las asociaciones futuras de la Marca-País, y siendo esta Marca-País el elemento diferenciador a través del cual se proyecta una imagen distintiva que se planifica o se forma de manera espontánea basada en un campo semántico 
diferente: representación artística, mediática, científica y política (Casado, 2006); es importante determinar cómo se forma dicha Imagen-País.

La imagen de un país, percibida por la opinión pública tanto interna como externa, está formada por una serie de características que se ponen en primer plano, bien por el contraste con la propia cultura, bien por la semejanza con lo propio (Iglesias y Molina; 2008). Estos rasgos, que se inician como manifestaciones propias culturales de un sector del país, tienden a exagerarse y a generalizarse para toda la nación, y muchas veces ocurre que los estereotipos no son coherentes y su valoración suele ser extrema, positivamente o negativamente, sin matices (Zenker y Martin, 2011).

En este contexto, Anholt y Hildreth (2004) desarrollaron el "Hexágono de la Imagen de una Marca", donde exponen que seis dimensiones configuran la percepción de un país en el exterior y se compone de: turismo, exportación, política, cultura, inversión e inmigración y gente. Cada una de éstas actúa de forma independiente y a la vez al unísono en función de las distintas audiencias que tienen interés en y/o con el país en cuestión.

Este esquema, ampliamente desarrollado en el NBI (Nation Brand Index o Índice de Marca-País), ha demostrado ser una forma de medición de la capacidad que tienen los países para comunicar atributos, valores y características identificativas a audiencias claves; y de las seis dimensiones ha quedado evidenciado que el aspecto político tiene la mayor capacidad de transmitir y afianzar imágenes, por su naturaleza "noticiosa" en los medios de comunicación internacionales.

Mas allá de la influencia de los aspectos de la diplomacia pública, como de la política exterior, que suelen cubrir mucho centimetraje o tiempo al aire en los medios de comunicación, además de formar parte del hexágono de la MarcaPaís, la utilización de la política de un país como marca y simbología destinada a lograr el apoyo de la población de otros países a su política exterior, es una forma de abordaje de la realidad novedosa que involucra una concepción posmoderna de la imagen y la reputación de un Estado (Van Ham, 2001), que involucra concebir una nueva forma de "poder" político. 


\section{EL PODER BLANDO}

Kagan (2003) promulgó la teoría del poder blando y el poder duro como manera de abordar la política exterior. El poder blando es la capacidad de persuadir e influir en actores políticos a través de medios culturales e ideológicos, pero sin usar el poder coercitivo. El poder duro es la capacidad de influir en los asuntos y en los demás actores políticos usando la fuerza y medidas coercitivas.

Por su lado Nye (2003: 30) desarrolló con detalle el poder blando como la capacidad de "lograr que otros ambicionen lo que uno ambiciona", y esto aplica a la posibilidad de conseguir que otros estados o naciones alineen sus intereses de política exterior a otro. El autor describe que "hay una forma indirecta de ejercer el poder. Un país puede obtener los resultados que desea porque otros países quieran seguir su estela, admirando sus valores, aspirando a su nivel de prosperidad".

Este concepto de poder blando engloba una serie de intangibles asociados a las naciones. Lo interesante de este concepto es que el Estado-Nación no tiene control sobre la mayor parte de ellos porque son producidos en la economía de mercado y la sociedad civil por medios de comunicación, empresas, ONG, entre otros, a diferencia de lo que sucede en el poder duro, donde el control es mucho más directo, por ejemplo con las capacidades militares.

Siguiendo esta lógica de pensamiento, Nye (2004) sugiere que el poder blando es cualquier recurso, siempre y cuando esté revestido de legitimidad. Keohane y Grant (2005: 37) apuntan a que "la reputación (de un país) sirve de mecanismo de control en ausencia de otros mecanismos, pero también en conjunción con ellos" sugiriendo que esta reputación opera en todos los contextos de la acción internacional de los Estados.

Es precisamente en la necesidad de reputación y credibilidad donde la MarcaPaís y, por ende, las estrategias de mercadeo asociadas a este fin, entran a 
jugar un papel predominante en la esfera de diplomacia pública internacional. Es en este contexto donde el concepto se adentra al terreno subjetivo, siendo el reconocimiento la variable clave, porque la percepción y la (des)legitimación son partes esenciales del poder blando, ya que a través del mismo se pueden trabajar dos capacidades bien distintas: la de atraer y configurar las preferencias (ideología); siendo esta última la de mayor poder de resultados.

\section{IMPLICACIONES DE UN ESTADO-POSMODERNO}

Noya (2005) desarrolló un esquema para vincular las diversas características del poder donde se presentan tres categorías bien diferenciadas:

Tabla No. 1:

Evolución del Poder de los Estados

\begin{tabular}{|c|c|c|}
\hline $\begin{array}{c}\text { Estado Pre- } \\
\text { Moderno } \\
\text { Poder Duro }\end{array}$ & $\begin{array}{c}\text { Estado } \\
\text { Moderno } \\
\text { Poder Duro }\end{array}$ & $\begin{array}{c}\text { Estado Pos- } \\
\text { Moderno } \\
\text { Poder Blando }\end{array}$ \\
\hline $\begin{array}{c}\text { Tamaño } \\
\text { geográfico }\end{array}$ & Economía & Cultura \\
\hline Población & Tecnología & Democracia \\
\hline & Militar & Lengua \\
\hline & & $\begin{array}{c}\text { Ayuda y } \\
\text { Cooperación }\end{array}$ \\
\hline
\end{tabular}

Fuente: Noya (2005)

Ahora bien, si es la percepción, las asociaciones y, en definitiva, la legitimación el punto clave de las características del poder blando (cultura, democracia, lengua, ayuda y cooperación), la pregunta que surge de esta discusión es: ¿Socialmente quienes son más permeables a la influencia del poder blando? Según Gertner (2007), en estratos sociales altos se priva la importancia de los 
factores simbólicos del poder blando y se llega a despreciar a las manifestaciones del poder duro.

Esta distinción determina una segmentación psicográfica clara para cualquier plan de diplomacia pública que quiera emplear la Marca-País como herramienta de persuasión: naciones o sociedades con estilos de vida posmodernos son más susceptibles al poder blando que sociedades con estilos de vida más materialistas o modernos.

\section{LA MARCA-PAÍS COMO POLÍTICA DE ESTADO}

En palabras de Van Han (2008:145) "La Marca-País se centra en conceptos como valores, normas y reglas en la política internacional". Este tratamiento involucra una nueva forma de entender las relaciones y la capacidad persuasiva de los Estados en el contexto internacional. Tanto para la MarcaPaís como para la diplomacia pública, el elemento clave es construir relaciones personales e institucionales y desarrollar un diálogo con el público extranjero basándose en valores compartidos. Este nuevo proceso se antepone al clásico tratamiento de los "issues" o "asuntos" típicos de diplomacia clásica, y amerita un tratamiento previo y constante a través de los medios de comunicación masivos.

A este planteamiento se adiciona que las decisiones de política del gobierno del país tienen influencia sobre la formación de imagen, y ahora los responsables políticos son mucho más cercanos a los medios internacionales de lo que solían ser. Es a través de estos medios que las naciones envían mensajes sobre ellos la mayor parte del tiempo, y esto es el efecto de acumulativo del que durante los años, crea sus marcas. "Los países pueden influir en su imagen si ellos tienen clara la idea de lo que ellos realmente significan, y si este mensaje sale clara y coherentemente" (Anholt y Hildreth, 2004:15). 
Al respecto, autores como Papadopoulos, et. al. (2000:95) sostienen que "la hostilidad política o militar, actitudes nacionalistas, costumbres locales, religión, comida y atracciones turísticas no tienen nada que ver con el desarrollo de un país y, sin embargo, afectan su imagen y sus dimensiones".

Al respecto, Casado (2006) advierte que cuando un país trasciende al mundo con informaciones de hechos negativos, especialmente a través de la prensa, los especialistas consideran que es preferible generar nuevas asociaciones positivas para refutar los aspectos negativos que se asocian con el país. Montesinos (2005) comparte esta opinión al afirmar que una imagen de país puede reforzar, si es fuerte y positiva, o debilitar, en caso de ser negativa, la imagen de un producto o marca.

La presencia exterior de cada nación depende, en mayor medida, de la potencia de sus instituciones y sobre todo, de la capacidad de fijar una imagen solvente de su oferta al mundo. Esta capacidad es un activo intangible asociado a la comunicación, ya que se refiere a la habilidad por sintetizar un perfil y su eficacia en comunicarlo. Por otro lado, esta comunicación no es algo puntual, es talento para informar e incorporar noticias en los canales adecuados.

Al respecto, Iglesias y Molina (2008:111), señalan "que la globalización y la revolución mediática han provocado que cada Estado sea más consciente de sí mismo, de su imagen, de su reputación, o lo que es lo mismo, de su marca". Esta concepción de los autores conlleva un cambio en los paradigmas políticos, una evolución que va desde el mundo moderno de la geopolítica y el poder militar hacia un mundo posmoderno de las imágenes y la influencia.

Por ello las EMP forman parte de la "nueva" diplomacia pública estatal, que incorpora los recursos tecnológicos de la sociedad moderna de las comunicaciones y el conocimiento (virtualidad en páginas web oficiales), a los recursos tradicionales de la diplomacia (diplomacia de embajadas, diplomacia de Cumbre, entre otros); dentro de la política de comunicación estratégica dirigida por el Estado a los diversos públicos objetivos (Iglesias y Molina, 2008). 


\section{CRÍTICAS A LA MARCA-PAÍS Y AL PODER BLANDO}

En la actualidad la discusión de la eficacia tanto del poder blando como de la Marca-País, está en pleno auge en los ámbitos académicos y profesionales.

Las críticas a los conceptos de Marca-País surgen desde dos áreas: aquellos sectores que consideran que un país no puede "etiquetarse" como una marca y que es imposible reducir su dignidad y su historia a un mero producto comercial (Rainisto, 2004), y las críticas que surgen de las falta de coherencia teórica dentro del mismo constructo, sus limitaciones y alcances.

Para los teóricos de la política internacional, la incorporación de marketing y relaciones públicas en los discursos de la diplomacia pública sigue es un tema candente de debate, ya que algunos expertos sostienen el punto de vista tradicionalista al entender esta intrusión como una contaminación de lo que ha sido una actividad puramente estatal (Melissen 2007), mientras que otros creen que la marca país y las relaciones públicas son hermanas en los más profundo de sus conceptos.

Cull (2008) plantes que lo más importante radica en que la labor de la diplomacia pública y la marca país gira en torno al eje de la construcción de relaciones, aunque con notorias diferencias que incluyen factores tales como los objetivos o resultados: Aumento de ventas frente a política exterior, los medios, y el tipo de comunicación, la gestión, la lengua y la cultura. Esta visión argumenta que, si bien la diplomacia pública y las Marcas-País no son en absoluto lo mismo, que son, al menos, complementarias entre sí

Adicionalmente la noción del poder posmoderno está sujeto a críticas, fundamentalmente por sus limitaciones inherentes. Según Blechman 
(2005:681) el poder blando "nunca será formado fundamentalmente por la acción gubernamental, ni tampoco podrá ser empleado en situaciones particulares". Esta crítica es profunda porque subyace en la idea que los políticos pueden controlar las herramientas del poder fuerte (sanciones económicas o intervenciones militares), mientras el empleo de las capacidades del poder blando (influencia de la cultura, marca-país, marcas comerciales, democracia) pueden ser de difícil aplicación.

\section{CONSIDERACIONES FINALES}

En palabras de Van Han (2008:145) "La Marca-País, como parte del poder blando, se centra en conceptos como valores, normas y reglas en la política internacional". Este tratamiento involucra una nueva forma de entender las relaciones y la capacidad persuasiva de los Estados en el contexto internacional. Tanto para la Marca-País como para la diplomacia pública, el elemento clave es construir relaciones personales e institucionales y desarrollar un diálogo con el público extranjero basándose en valores compartidos. Este nuevo proceso se antepone al clásico tratamiento de los "issues" o "asuntos" típicos de diplomacia clásica.

Así pues, dentro de las reglas internacionales, el diálogo basado en la cultura, simbología, Marca-País y democracia, se constituyen en normas y referencias de conducta que pueden inducir el comportamiento de estados, sin que ellos perciban que se está afectando sus identidades o sus intereses.

Al entender que las herramientas del poder blando subyacen en la cultura internacional de las naciones en la forma de normas y reglas de conducta por las cuales se rigen los estados, es necesario explorar una visión interdisciplinaria para estructurar procesos más eficientes para emplear dichas capacidades, donde el manejo de la realidad cultural como base para el desarrollo del capital de marca (Saavedra, 2007) toma relevancia y donde el 
constructivismo, como estructura teórica, asume que las personalidades o identidades de los Estados son variables, que dependen del contexto histórico, cultural, político, y social.

Este continuo teórico basado en el constructivismo de Valores-SimbologíaCultura-Capital de Marca asume que las identidades son contextuales y maleables en el tiempo. Sin embargo, aún queda mucho cuerpo teórico por construir desde el constructivismo para explicar y generar modelos que permitan a los hacedores de políticas públicas contar con herramientas de alcance internacional (principal debilidad teórica constructivista) capaces de llevar a buen término los planes de persuasión e influencia política de sus Estados.

\section{REFERENCIAS BIBLIOGRÁFICAS}

Anholt, S. (2008). Las marcas país. Revista Estudios internacionales, (161), 193-197.

Anholt, S. y Hildreth, J. (2004), Brand America: The Mother of all Brands, Cyan Books, London, UK.

Blechman, B. (2005), Book review: Nye's Soft power. Political Science Quarterly. Vol. 119. No. 4. Pp. 680-81.

Borsay, P. y Proudfoot, L. (2002) Provincial towns in early modern England and Ireland : change, convergence and divergence (Proceedings of the British Academy, 108). Oxford: Oxford University Press for the British Academy. Pp. 1-27.

Casado, S. (2006). "Estudio sobre la Marca País en el mundo". EN: Boletín Especial de Imagen y Comunicación de la Universidad de Congreso. № 2, Año 1. Mendoza, Argentina. p. 6-11.

Casilda, R. (2001) La Marca-País como ventaja competitiva. Centro Virtual cervantes. Anuario 2001 
Cull, N. (2010). Public Diplomacy: Seven Lessons For Its Future from Its Past. [Recuperado Enero 30 2012]. de: http://ics.leeds.ac.uk/papers/vp01.cfm?outfit=pmt\&requesttimeout $=500 \& f$ older $=7 \&$ paper $=3028$

Fan, Y. (2006). Branding the nation: What is being branded? Journal of Vacation Marketing, 12(1), 5-14.

Galiano, J. (2002). La Marca España como oportunidad y como reto: Mucho más que una imagen. Investigación y Marketing. No. 76. Pp.36-46

Gertner, D. (2007). Place Branding: Dilemma or Reconciliation between Political Ideology and Economic Pragmatism? [Recuperado Enero 30 2012]. De http://www.palgrave-journals.com/pb/journal/v3/n1/full/6000053a.html

González, E. y Casilda, R. (2002). La marca país como ventaja competitiva. El valor de la marca España. Revista ICE, № 799 (abril-mayo).

Homs, R. (2004), La era de las marcas depredadoras. Editorial McGraw Hill Interamericana Editores, S.A.

Iglesias, M., y Molina, D. (2008). La estrategia marca país en la sociedad informacional: los casos de España y Ecuador. Historia Actual Online, 109-126.

Kagan, R. (2003), Poder y debilidad, Taurus, Madrid.

Keohane, R. y Grant, R. (2005), Accountability and Abuses of Power in World Politics. American Political Science Review, Vol. 99. No. 1.

Kotler, P., Jutusripitak, S. y Maesincee, S. (1999), The Marketing of Nations: A Strategic Approach to Building National Wealth. The Free Press, New York.

Lucarelli, A., \& Berg, P. O. (2011). City branding: a state-of-the-art review of the research domain. Journal of Place Management and Development, 4(1), 9-27.

Melissen, J. (2007). The New Public Diplomacy: Between Theory and Practice. En: J. Melissen, Ed. The New Public Diplomacy: Soft Power in International Relations. New York: Palgrave Macmillan

Montesinos, M. (2005). "Importancia relativa de la marca y efecto país de origen sobre la intención de compra de los consumidores". EN: 
Publicación Decisiones de Marketing. Volumen 21, № 4. Valencia, España. p. 6, 7 y 8.

Noya, J. (2005), El poder simbólico de las naciones, Instituto Real Alcano. España. Documento de Trabajo (DT) 35 /2005

Nye, J. (2003), La paradoja del poder norteamericano, Taurus, Madrid.

Nye, J. (2004), Soft Power, PublicAffairs, Nueva York.

Papadopoulos, N., Heslop, L. e Ikon Research Group (2000). "A Cross-national and Logitudinal Study of Product-Country Images with a Focus on the U.S. and Japón", Marketing Science Institute Working Paper Series, 00106.

Rainisto, S. (2004), Opinion pieces: Where is place branding heading. Place Branding, Vol. 1, No. 1. Pp. $12-35$.

Saavedra, J. (2007), Capital de marca como fenómeno cultural: El método etnográfico como herramienta de medición en mercadeo. Espacio Abierto. Vol. 16. No. 4. Pp. 715-729.

Sánchez, J., Cubillo, J. y Cerviño, J. (2005). Influencia de posicionamiento competitivo de las empresas en el efecto "Made in Spain" y éxito empresarial. Información comercial española (ICE), (827), 261-276.

Seisdedos, H. (2006), Marca Ciudad Como Antídoto Para La Bonsainización Del City Marketing. Harvard Deusto Marketing \& Ventas, No.76. Pp. 7279.

Van Ham, P. (2001), The rise of the brand state, Foreign Affairs. Vol. 80, No. 5. Pp. 2-6.

Van Ham, P. (2005), Power, public diplomacy, and the Pax Americana, in Melissen, J. (ed) 'The New Public Diplomacy: Soft Power in International Relations', Palgrave Macmillan, Pp. 47-66.

Van Ham, P. (2008), Place Branding: The State of the Art. The Annals of The American Academy of Political and Social Science. Pp. 1-24

Ward, S. (1998). Selling Places. The Marketing and Promotion of Towns and Cities, 1850-2000. Routledge, New York.

Zenker, S., y Martin, N. (2011). Measuring success in place marketing and branding. Place Branding and Public Diplomacy. Vol. 7, No. 1. Pp. 32-41 
Para citar este artículo 